Review

\title{
Coordination Modes and Different Hapticities for Fullerene Organometallic Complexes
}

\section{Delia Soto and Roberto Salcedo *}

Institute of Materials Research, National Autonomous University of Mexico, External Circuit, University City, Coyoacan 04510, Mexico City, Mexico

* Author to whom correspondence should be addressed; E-Mail: salcedo@unam.mx.

Received: 10 April 2012; in revised form: 22 May 2012 / Accepted: 1 June 2012 /

Published: 12 June 2012

\begin{abstract}
The different coordination modes in fullerene organometallic complexes are reviewed. The main modes are $\eta 2$ and $\eta 5$, but there are some interesting studies about the other four, all of them are revised in order to show which is the state of art of this kind of compounds with the respect of the hapticity.
\end{abstract}

Keywords: fullerene; exo organometallic complexes; hapticities

\section{Introduction}

Studies of the organometallic and coordination chemistry of fullerenes started [1,2] immediately after the first reported preparation [3] of these wonderful molecules [4]. Fullerenes have extraordinary capabilities to coordinate metal atoms, both inside (endohedral) and outside (exohedral) the carbon cage. This review will focus on the several kinds of exohedral metallofullerenes in which the metal atom can coordinate with a specified number (n) of carbon atoms in the surface of the cage (hapticity). There have been several good reviews examining various aspects of exohedral and endohedral organometallic complexes of fullerenes [5-7]. Good reviews also exist which discuss the exo-organometallic complexes of fullerenes [8,9]. A number of different features found in these species are considered, however one important topic related to these molecules concerns variations in hapticity and their consequences; this topic has not yet been reviewed and will be the subject of our study. 


\section{The Possibilities of Hapticity}

An interesting characteristic of fullerenes is that in spite of their marked symmetry, they have several different coordination positions. Fullerene can be doubly substituted [in $(6,6)$ fashion] giving regioisomers that have been studied and for which Hirsh has proposed a nomenclature [10]. Taking this nomenclature as a starting point, it is relatively easy to distinguish a point of reaction and possible isomers (see Figure 1); we can have either three cis isomers with addenda on the same hemisphere, or an equatorial isomer and four trans isomers with addenda on the opposite hemisphere.

Figure 1. Regiochemistry of double addition to fullerene $\mathrm{C}_{60}[10]$.

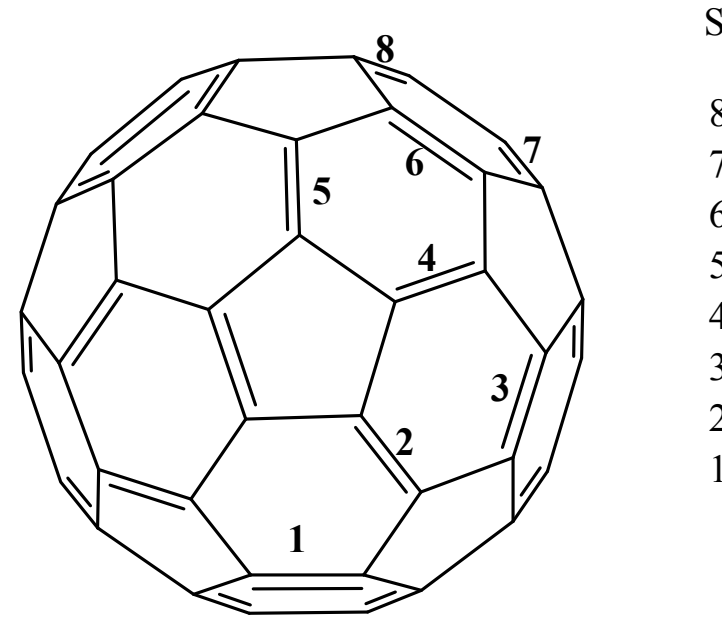

$\begin{array}{ll}\text { Isomer } & \text { Maximum } \\ & \text { Symmetry } \\ \text { cis-1 } & \mathrm{Cs} \\ \text { cis-2 } & \mathrm{Cs} \\ \text { cis-3 } & \mathrm{C}_{2} \\ \text { equatorial } & \mathrm{Cs} \\ \text { trans-4 } & \mathrm{Cs} \\ \text { trans-3 } & \mathrm{Cs} \\ \text { trans-2 } & \mathrm{Cs} \\ \text { trans-1 } & \mathrm{D}_{2 \mathrm{~h}}\end{array}$

Lichtenberger [11,12] and his co-workers carried out very interesting theoretical studies on this topic, considering all possible interactions between fullerene $\mathrm{C}_{60}$ and a palladium atom. Similarly Sokolov [13] suggested a very useful classification of the coordination modes. All these ideas have been resumed in the following list and in Figure 2.

Figure 2. Presenting all possible hapticities for fullerene $\mathrm{C}_{60}$.

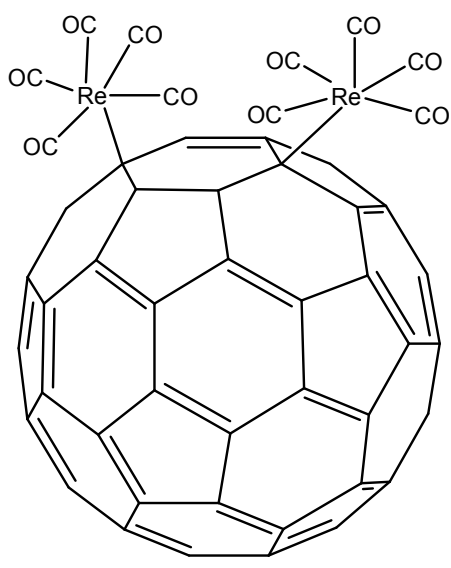

$\eta^{1}$

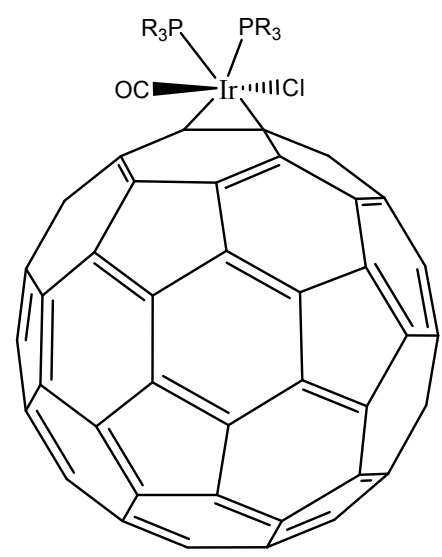

$\eta^{2}$

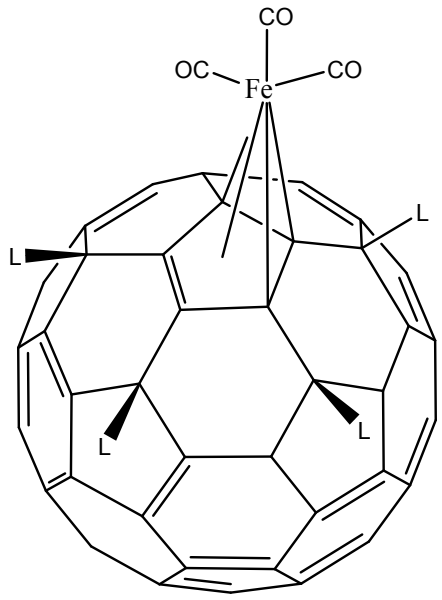

$\eta^{3}$ 
Figure 2. Cont.

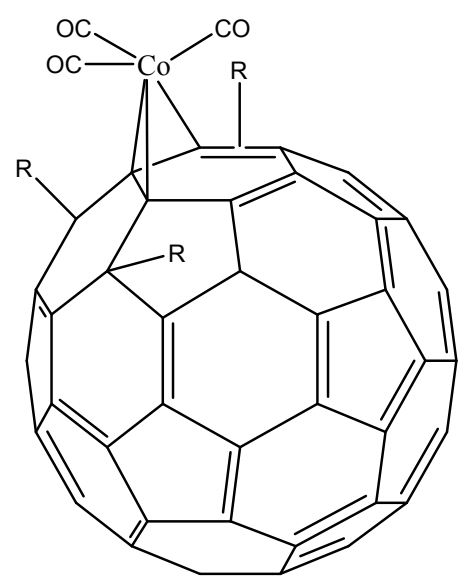

$\eta^{4}$

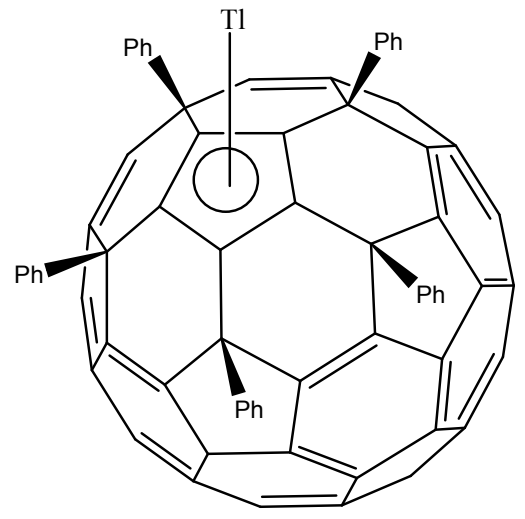

$\eta^{5}$

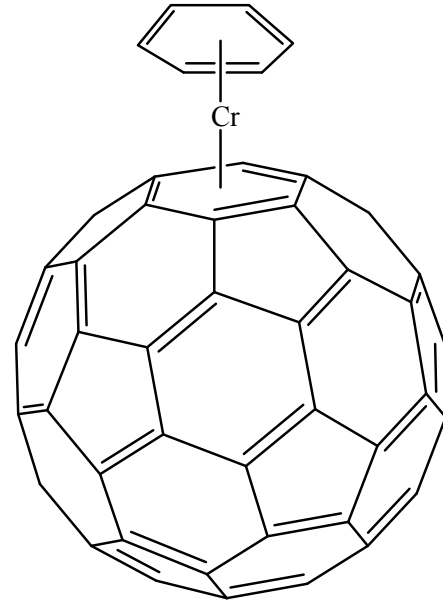

$\eta^{6}$

- $\quad \eta^{1}$ hapticity with the metal atom directly above any carbon atom (an $\sigma$ bond is expected);

- $\quad \eta^{2}$ hapticity; this may be $(6,6)$ or $(6,5)$ type, although the last of these is not common;

- $\quad \eta^{3}$ hapticity; the metal atom linked to three carbon atoms, theoretically this could be on either a six or five-member ring;

- $\quad \eta^{4}$ hapticity, the metal atom linked to four carbon atoms;

- $\quad \eta^{5}$ hapticity, metal atom linked directly above the center of a five-member ring;

- $\quad \eta^{6}$ hapticity, metal atom linked directly above the center of a six-member ring.

Theoretically it is possible to produce examples of all six items; however in practice there are strong limitations, therefore each of these cases will be presented in turn.

\section{3. $\eta^{1}$ Hapticity}

This coordination mode is a little ambiguous because it represents the only example where the bond is $\sigma$, however there are certain small examples where there is only one bond $(\sigma)$ between a fullerene and a metal atom [14-16]; likewise there are some cases where a complex can manifest a very complicated coordination, but some of the bonds present a possible $\sigma$ coordination [17]. Besides this, a number of interesting theoretical studies exist, discussing this aspect as well as other features meriting comment [18].

The salient point referring to this type of coordination is the nature of the bond $\sigma$ (as this represents the only type of compound with this type of bond) or $\pi$. There have been interesting discussions about "hapticity" involving only one carbon atom, for example the possible accommodation found in $\mathrm{C}_{60}\left\{\mathrm{Ag}\left(\mathrm{NO}_{3}\right)\right\}_{5}[19]$ or the clusters of triosmium in the complexes prepared by Park [20] (see Figure 3). Indeed this coordination seems to be neither stable, nor strong. There are also some interesting ionic derivatives $[21,22]$ for which the presence of the $\sigma$ bond and its relevance have been described and these have been most elegantly studied by applying x-ray crystallography and theoretical calculations. In this case, the authors find that the bond between fullerene and the metal atom (cobalt) is larger than usual and in some way stabilized by the crystal lattice. 
Figure 3. Model of a compound with $\eta^{1}$ hapticity occurring in a single bond [20].

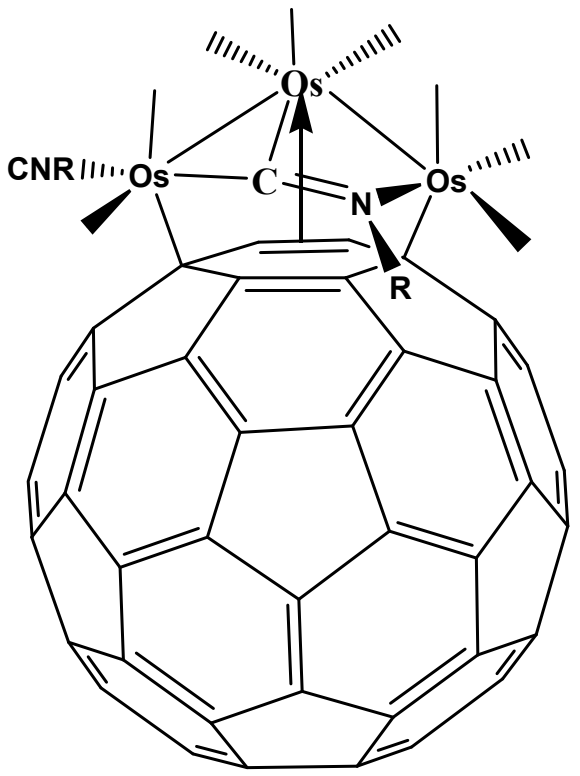

There are some cases where the defined structure is not clear and therefore the probability of a structure which includes a $\sigma$ bond has been suggested, although there are other possible explanations [23]. Cases like this require a lot of work in order to confirm the existence of this particular coordination.

Theoretical studies referring to this ubiquitous coordination are not common; the $\eta^{1}$ coordination has been considered more as a possible step in a reaction or fluxional process [11,12] than as a defined structure. Almost all the available information referring to this topic has been discussed here, however it is important to note the interesting theoretical analysis carried out by Park and his group [18] where the electronic population of the bonds involved in the interaction of the metal plays a fundamental role in explaining hapticities $\eta^{1}, \eta^{2}(6,5)$ and $\eta^{2}(6,6)$. They claim that $\eta^{2}(6,6)$ should represent the most stable structure out of the three in the case of neutral molecules, but the ionization of these as a result of successive electron reduction produces a stable $\eta^{1}$ ( $\sigma$ bond) species [24], therefore this may be a good strategy for preparing compounds of this kind.

\section{4. $\eta^{2}$ Hapticity}

The case of $\eta^{2}$ is very different from the first example and many reports deal with this coordination mode $[5,13]$. The main outstanding factor is that practically all the organometallic complexes of this kind have been described as forming the bond in a $(6,6)$ fashion, i.e., the $\pi$ bonds are always formed in the junction of two six-member rings at the fullerene surface. The hapticity example pertaining to the $(6,5)$ type previously mentioned in the Park study [18] may be important and will be analyzed at the end of this section.

Fullerene can be doubly substituted [in $(6,6)$ fashion] giving eight regioisomers as previously mentioned [10]. A short time after the discovery of $\mathrm{C}_{60}$ (and other fullerenes), the organometallic chemistry of these compounds started with the first reports describing these kinds of substance, with the possibility of producing stable $\eta^{2}$ derivatives $[1,25,26]$. However work in this area is still ongoing [27,28]. 
The great majority of fullerene organometallic compounds with an undisturbed electronic system involve only $\eta^{2}$ coordination (Figure 4). Thus, it has been suggested [16] that the chemistry of this kind of compound might be similar to that found in the isolated olefinic double bond, where the non-planarity of the fullerene surface compels the orbitals outside this plane not to be completely parallel and therefore the $\eta^{5}$ and $\eta^{6}$ coordination manifest bonding problems with a predictable resultant distortion in the formation of the sphere. This feature is a consequence of the limited $\pi$ conjugation of the fullerene species and it has been suggested [29] that the source of this limitation is precisely its curvature which causes an energetically unfavorable arrangement for the double bonds. Indeed this was also the reason for the predominance of the $\eta^{2}$ coordination, where there is a lower demand on $\pi$ orbitals, than on the other hapticities.

Figure 4. Typical $\eta^{2}$ fullerene organometallic complex [5].

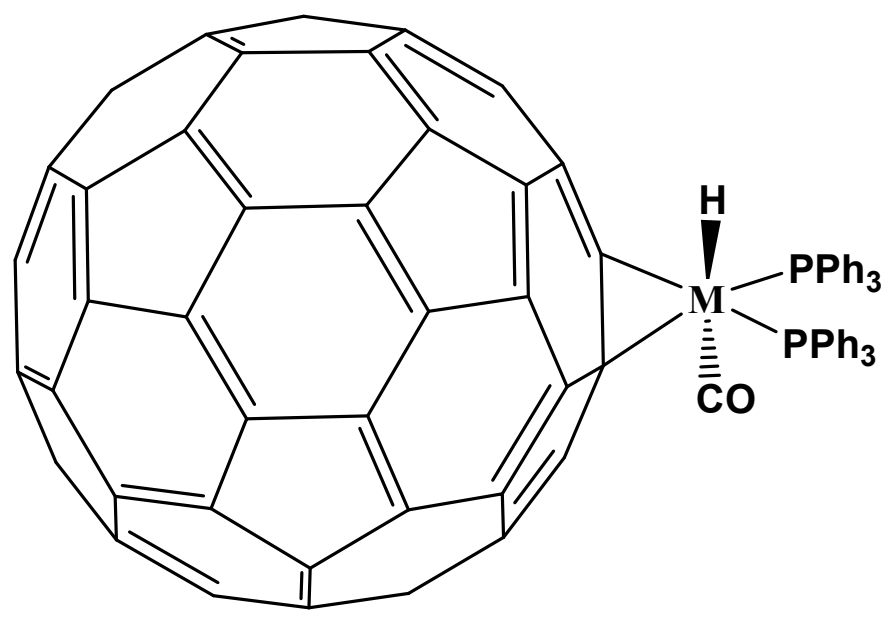

An excellent theoretical work provides an accurate description of the features found in this kind of compound. This article by Sgamellotti and his group [30] provides an analysis based on the DewarChatt-Duncanson model (DCD) that was developed in order to explain the nature of the bond between the double bond of olefins and metal atoms, therefore it should be useful also to explain the bond in the fullerene $\eta^{2}$ complexes. The DCD model propose two bond components, the first one is the donor acceptor interaction ( $\sigma$ type) whereas the second one the dative component ( $\pi$ type), both have important contribution, the first is the responsible of the electronic transfer from the olefin to the metal and is described as the interaction between an empty orbital of the metal and the filled $\pi$ orbitals of the ligand. The second one involves the back-bond in reverse sense that arises from the interaction between an occupied d-orbital of the metal and a nonbonding $\pi^{*}$ molecular orbital of the olefin, this last one interaction should be particularly important in the case of fullerene complexes because this last kind of orbitals has large population and is very near the occupied orbitals, therefore the interaction can be strong $[31,32]$. The authors elegantly demonstrate that the bond makes several contributions and the $\pi$ back-donation representing the dominant one of these, turns out to be even more important than the direct $\sigma$ donation. Another interesting point here is that the $(6,6)$ double lost its intrinsic double character, demonstrating a length increase that follows the $\mathrm{Pd}<\mathrm{Ni}<\mathrm{Pt}$ order, as well as corresponding bond energy terms and the concomitant $\mathrm{C}_{60}$ distortion. The same bond energy 
terms are higher for fullerene than the corresponding ethylene complexes, when an analogue $\pi$ bond is present (together with unsubstituted ethylene).

Other theoretical works have focused on the stability of all the different possible coordination modes. The works of Lichtenberger and his group [11,12] have been mentioned previously, where they found that the only possible stable coordinations for unperturbed fullerene $\left(\mathrm{C}_{60}\right)$ are $\eta^{2}$ and $\eta^{5}$, with the former being the most probable, and with all other cases (with the particular exception of the $\sigma \eta^{1}$ cases) being repulsive. Likewise in his study, Loboda [33] presents similar results to those of Lichtenberg, but furthermore he suggests that the strongest $\mathrm{M}-\mathrm{C}_{60}$ bond will be that pertaining to the complex manifesting a large HOMO-LUMO gap, so that the elements in the fourth and fifth series of the periodic table will demonstrate better bonds than those in the third row; referring in all cases to $\eta^{2}$ hapticity.

The addition of fragments containing metal atoms in $\eta^{2}$ fashion does not greatly affect the electronic distribution on the entire sphere of fullerene, especially in zones far from the coordination and neither does its intrinsic electron affinity change; so that it is possible to envisage multiple substitution taking place at the surface of the sphere or even on the same hexagon. It is also possible to find compounds where the coordination mode is $\eta^{2}$ but they support multiple substitutions on the same face of the sphere [34] (see Figure 5) or several substitutions on different faces [35] (see Figure 6). However all these kinds of compounds belong to the same coordination mode, therefore the $\eta^{2}$ has ample versatility in terms of design or for the creation of new substances.

The $(6,6)$ coordination mode for this particular hapticity is a consequence of electron richness because the "best" double bonds for an olefinic coordinative substitution should be those corresponding to the six-member rings, as well as those implicated in weak aromatic systems i.e., the hexagon-hexagon fragments. This is because it has been suggested that six-member faces constitute weak aromatics, whereas five-member faces are anti-aromatic [36].

Figure 5. A complex with several $\eta^{2}$ substitutions in one face [5].

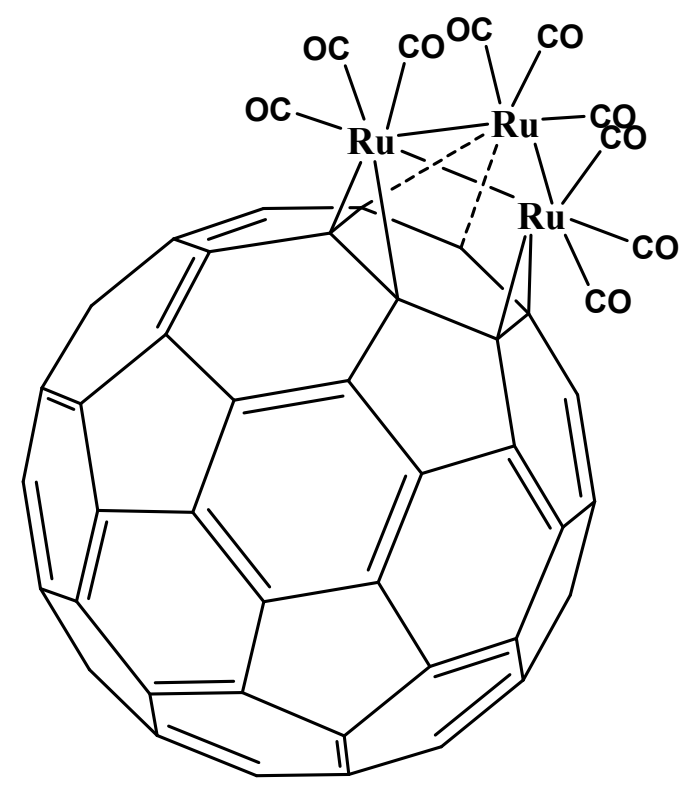


Figure 6. A complex with several $\eta^{2}$ substitutions in different faces [5].

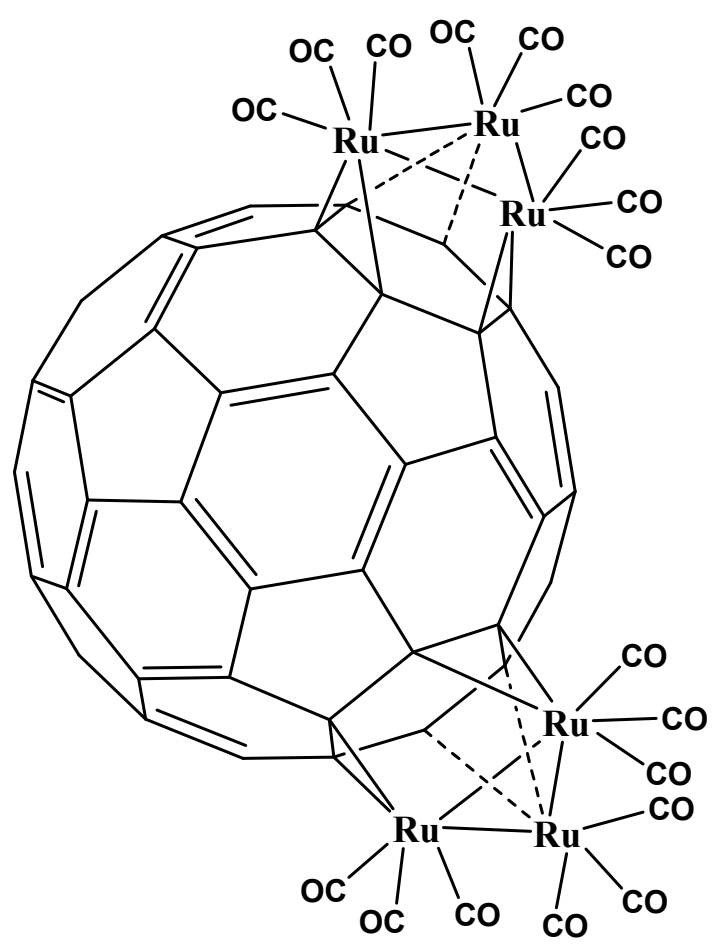

With respect to the $\eta^{2}(6,5)$ mode, Park and his group have made interesting theoretical propositions in the same paper mainly focusing on the $\eta^{1}$ mode [18], arriving at the conclusion that in multiple substitutions and ionic species, the $\eta^{2}(6,5)$ mode may be more stable than its $(6,6)$ counterpart. This phenomenon may be a consequence of both steric effects and a change in the electronic distribution of the ions.

\section{5. $\eta^{3}$ and $\eta^{4}$ Hapticities}

The formation of $\eta^{3}$ and $\eta^{4}$ complexes of fullerene with transition metals does not produce stable systems because the fullerene has an extended conjugated system and the fragments have low polarizability, involving three or four atoms interacting with metals. Thus, the way to form complexes with hapticities 3 and 4 is to modify the fullerene structure by either adding radicals to certain carbon atoms or by replacing certain carbon atoms with hetero-atoms. These are able to change the local structure of the frontier orbitals causing substantial stabilization to complexes, as a result of the transition metal atoms becoming coordinated to three or more carbon atoms. The most pronounced effect occurs when the conjugated system can be divided into two or more independent fragments [37].

Very few articles discuss $\eta^{3}$; however Stankevich [38] has provided a theoretical work. This article proposes the possible existence of $\eta^{3}$-complexes between allyl type derivatives of $\mathrm{C}_{60}$ fullerene $\left(\mathrm{C}_{60} \mathrm{R}_{3}\right.$ $(\mathrm{R}=\mathrm{H}, \mathrm{F}, \mathrm{Cl}, \mathrm{Br})$ ) and $\mathrm{Ni}$ or $\mathrm{Co}$, identified by means of DFT_PBE calculations. The study demonstrates that $\mathrm{C}_{60} \mathrm{R}_{3}$ ligands can form the stable species $\mathrm{C}_{60} \mathrm{R}_{3} \mathrm{Co}(\mathrm{CO})_{3}$ and $\mathrm{C}_{60} \mathrm{H}_{3} \mathrm{NiC}_{5} \mathrm{H}_{5}$, where the metal atoms are $\pi$-bonded to the fullerene carbon cage with $\eta^{3}$ hapticity (see Figure 7 ). 
Figure 7. $\eta^{3}$ hapticity model [38].

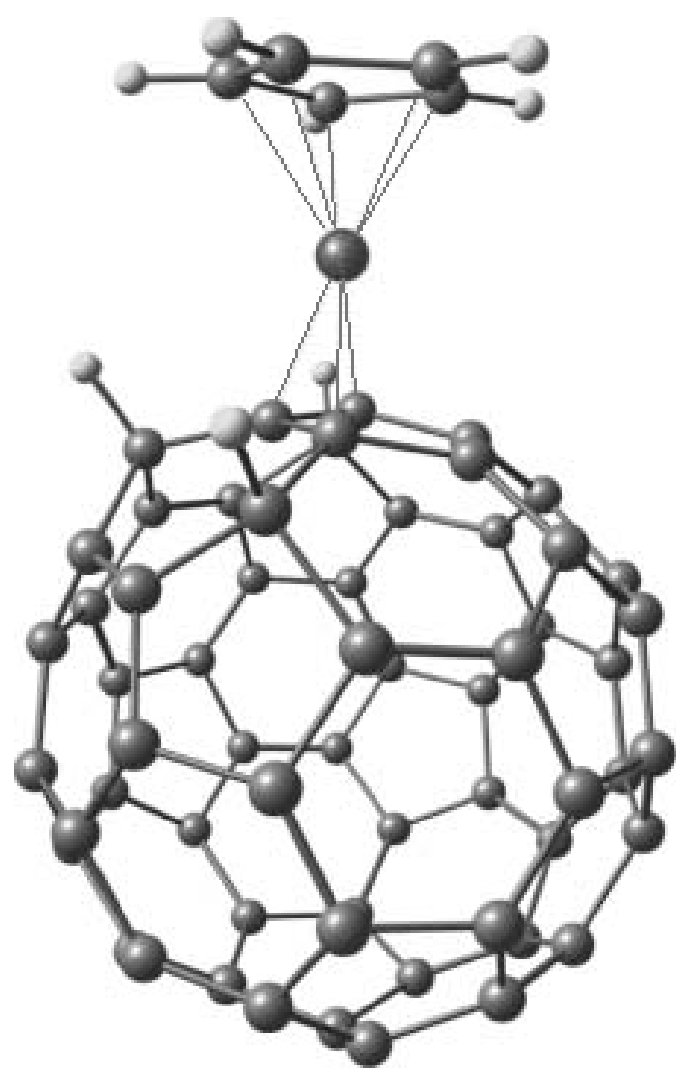

Rubin and his co-workers [39] have presented theoretical and experimental data referring to the existence of complexes comprising a pentaarylfulleride anion and $\mathrm{AuPPh}_{3}$ and $\mathrm{AgPPh}_{3}$. In conformity with the distances and angles of bonds between the metal and the cyclopentadienyl ring embedded in the fullerene, they observed several coordination modes ranging from $\eta^{1}$ with a slight distortion toward $\eta^{3}$ in the case of gold, and to $\eta^{2} / \eta^{3}$ in the case of silver.

The embedded fullerenyl cyclopentadienyl ring (Figure 8) displays a slightly distorted $\eta^{1}$ coordination to the $\mathrm{Au}\left(\mathrm{PPh}_{3}\right)$ fragment leaning toward $\eta^{3}$ (denoted $\left.\eta^{1} / \eta^{3}\right)$, with a principal $\mathrm{Au}(1)-\mathrm{C}(1)$ distance of 2.160(6) $\AA$ and secondary $\mathrm{Au}(1)-\mathrm{C}(2)$ and $\mathrm{Au}(1)-\mathrm{C}(5)$ distances of 2.823(7) and 2.782(5) $\AA$. In the case of silver (Figure 9), the principal $\mathrm{Ag}(1)-\mathrm{C}(1)$ distance of 2.259(4) $\AA$ and the secondary interactions $\mathrm{Ag}(1)-\mathrm{C}(2)$ and $\mathrm{Ag}(1)-\mathrm{C}(5)$ with distances of 2.525(4) $\AA$ 2.894(4) $\AA$, together with a reduction in the metal-ligand bond angles $\mathrm{Ag}(1)-\mathrm{C}(1)-\mathrm{C}(2)\left(82.7(2)^{\circ}\right)$ and $\mathrm{Ag}(1)-\mathrm{C}(1)-\mathrm{C}(5)$ $\left(100.8(2)^{\circ}\right)$, and likewise a corresponding increase in the angle $\mathrm{Ag}(1)-\mathrm{C}(1)-\mathrm{C}(9)\left(113.8(3)^{\circ}\right)$ are all factors pointing to an increase in the hapticity of metal-ligand bonding from $\eta^{1}$ to $\eta^{3}$.

The possibility of the formation of $\eta^{4}-\pi$-complexes of $\mathrm{C}_{60}$ with a $\mathrm{Fe}(\mathrm{CO})_{3}$ species was theoretically analyzed by Chistyakov and Stankevich, applying the DFT_PBE approach [40]. It was found that the attachment of four (or six) hydrogen atoms to $\mathrm{C}_{60}$ to form "butadiene"-or "fulvalene"-type derivatives of $\mathrm{C}_{60}$ fullerene, respectively, promotes the stabilization of $\eta^{4}$ - $\pi$-complexes of $\mathrm{C}_{60}$ derivatives with $\mathrm{Fe}(\mathrm{CO})_{3}$ unit, but even when the energies calculated are favorable, the comparison with the energies of $\eta^{5}-\pi$-bonds in ferrocene molecule $\left(110 \mathrm{kcal} \mathrm{mol}^{-1}\right)$ and $\eta^{5}-\pi-\mathrm{C}_{60} \mathrm{H}_{5} \mathrm{FeCp}\left(117 \mathrm{kcal} \mathrm{mol}^{-1}\right)$ and $\eta^{5}-\pi-\mathrm{C}_{40} \mathrm{H}_{5} \mathrm{FeCp}\left(116 \mathrm{kcal} \mathrm{mol}^{-1}\right)$ complexes shows the $\eta^{4}-\pi$-bonds to be weaker than the $\eta^{5}$ - $\pi$-bonds. 
Figure 8. Rubin's proposition for a $\eta^{1}$ to $\eta^{3}$ hapticity change in the case of a gold complex (Reproduced from [39] with permission).
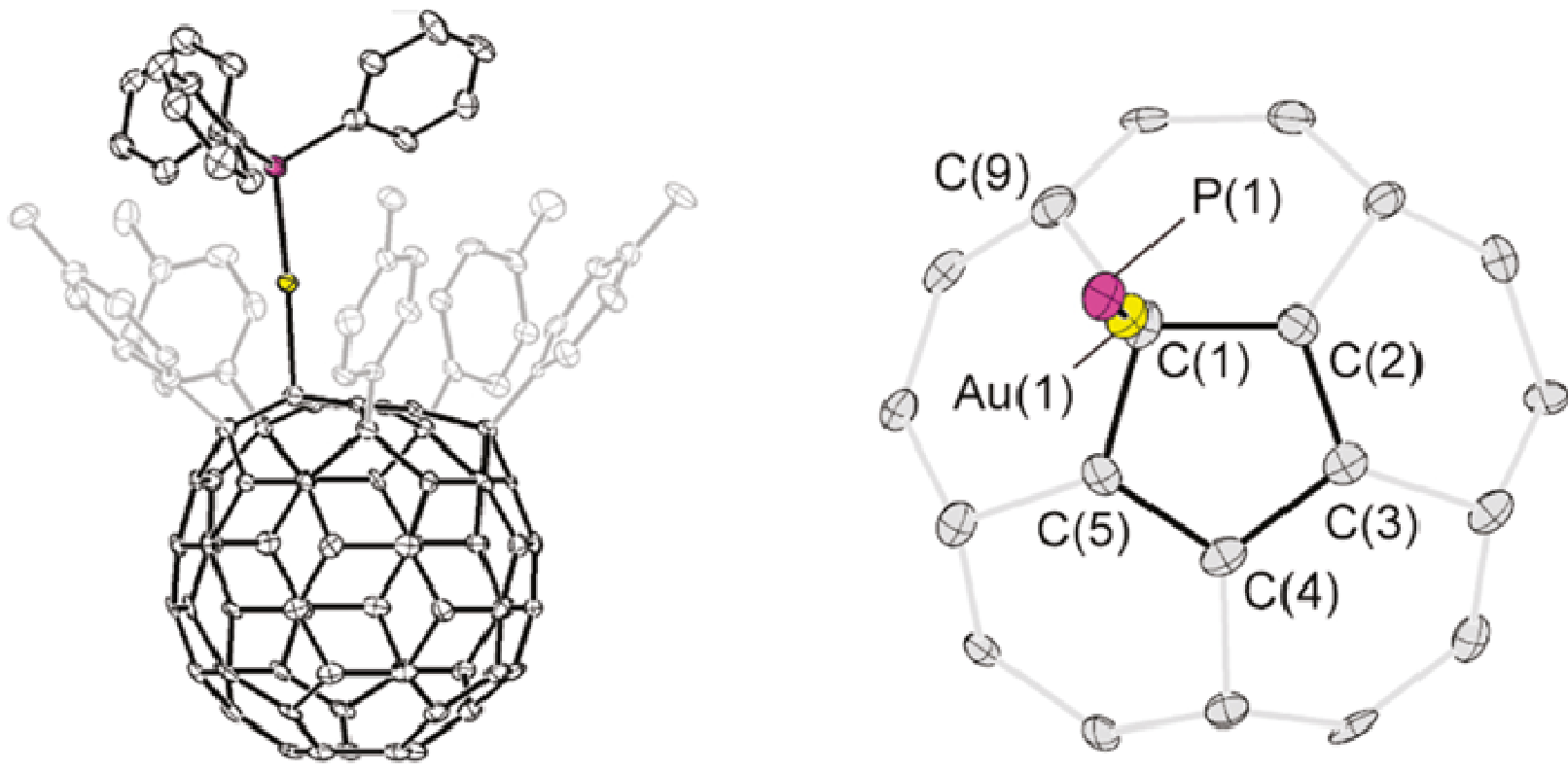

Figure 9. Rubin's proposition of $\eta^{3}$ hapticity for a silver complex (Reproduced from [39] with permission).
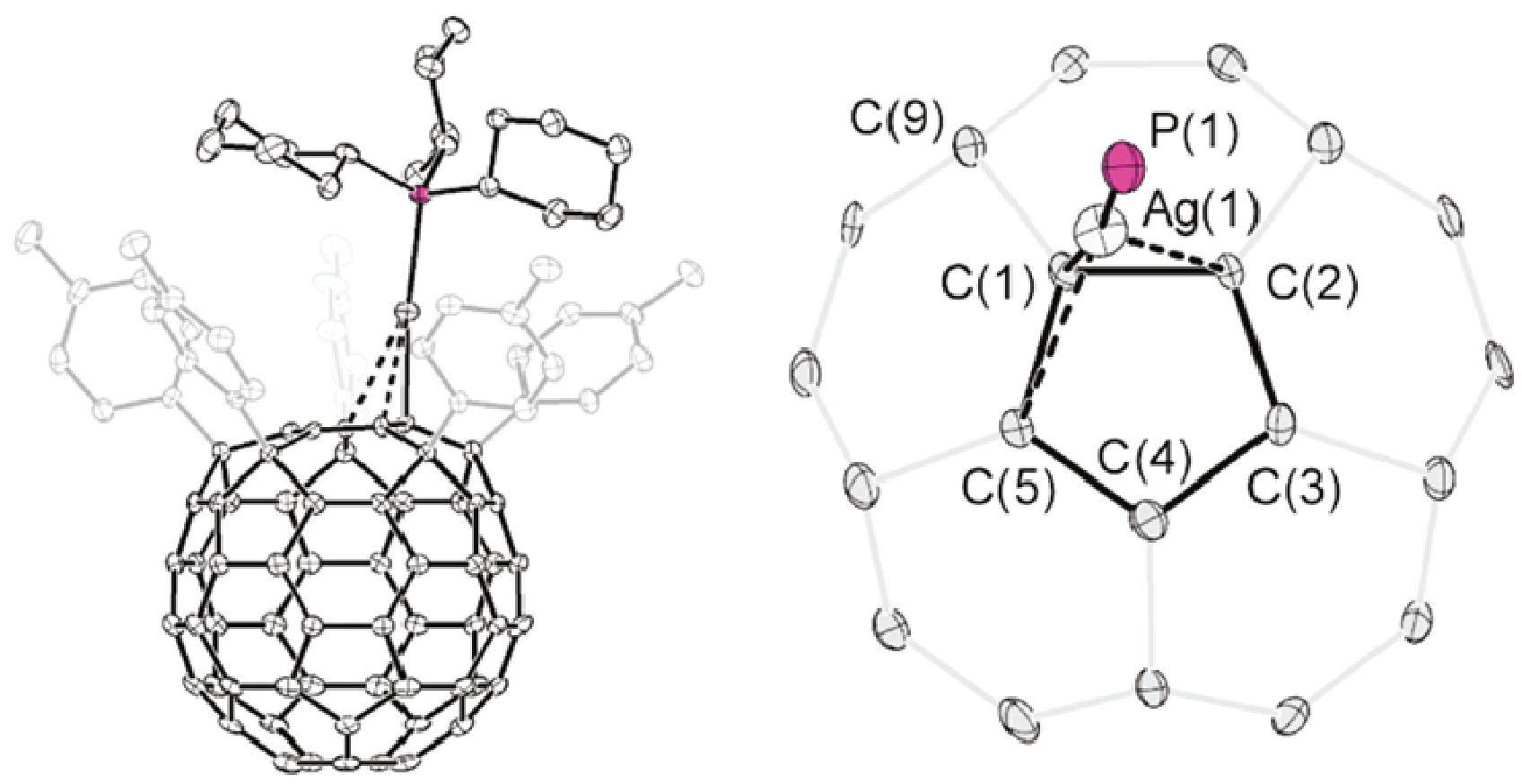

\section{6. $\eta^{5}$ Hapticity}

The formation of stable $\eta^{5}$-complexes between fullerenes and transition metals is highly improbable because the conjugated system is rather strongly delocalized, and the polarization of the atoms of the five-member face is weak. Lichtenberger [11,12], Sokolov [13], Loboda [33], Rogers [41] and Kang [42] have carried out theoretical analyses on this particular coordination mode. There is a suggestion that in order to disrupt the conjugated system, it is necessary to modify the fullerene structure by the addition 
of R groups, hydrogen $(\mathrm{H})$, methyl $(\mathrm{Me})$ or phenyl $(\mathrm{Ph})$, in the $\alpha$-position with respect to the same five-membered face. Chistyakov and Stankevich [43] in particular have suggested that the formation of the cyclopentadienyl ion in the fullerene is the key to forming complexes with transitional metals. Thus there are two challenges; one is to form a fence around the five-member ring and the other to impose the necessary ionization in order to produce the cyclopentadienyl group.

Nakamura and his coworkers accomplished this task [44]; they built a "fence" of five organic groups around the five-member ring and obtained the corresponding compounds. Practically all works in this field are derived from this group, for example they published [45] the synthesis of the first complexes called (pentamethylfullereno)/ferrocene which were synthesized in two steps from $\mathrm{C}_{60}$-fullerene with a $45 \%$ overall yield, based on their previous work with cyclopentadienyl $\left(\mathrm{C}_{60} \mathrm{R}_{5}\right.$, $\mathrm{R}=\mathrm{Me})$ and indenyl $\left(\mathrm{C}_{70} \mathrm{R}_{3}, \mathrm{R}=\mathrm{Me}\right)$, both metal complexes of fullerenes [46]. The distances between the pentagon carbon atoms and iron $(2.033 \AA$ for $\mathrm{Cp}$-Fe, and $2.089 \AA$ for FCp-Fe) are comparable to those in known ferrocene derivatives (see Figure 10).

Figure 10. Molecular structure of ferrocene $/ \mathrm{C}_{60}$-fullerene hybrid determined by $\mathrm{X}$-ray diffraction (reproduced from [46] with permission).

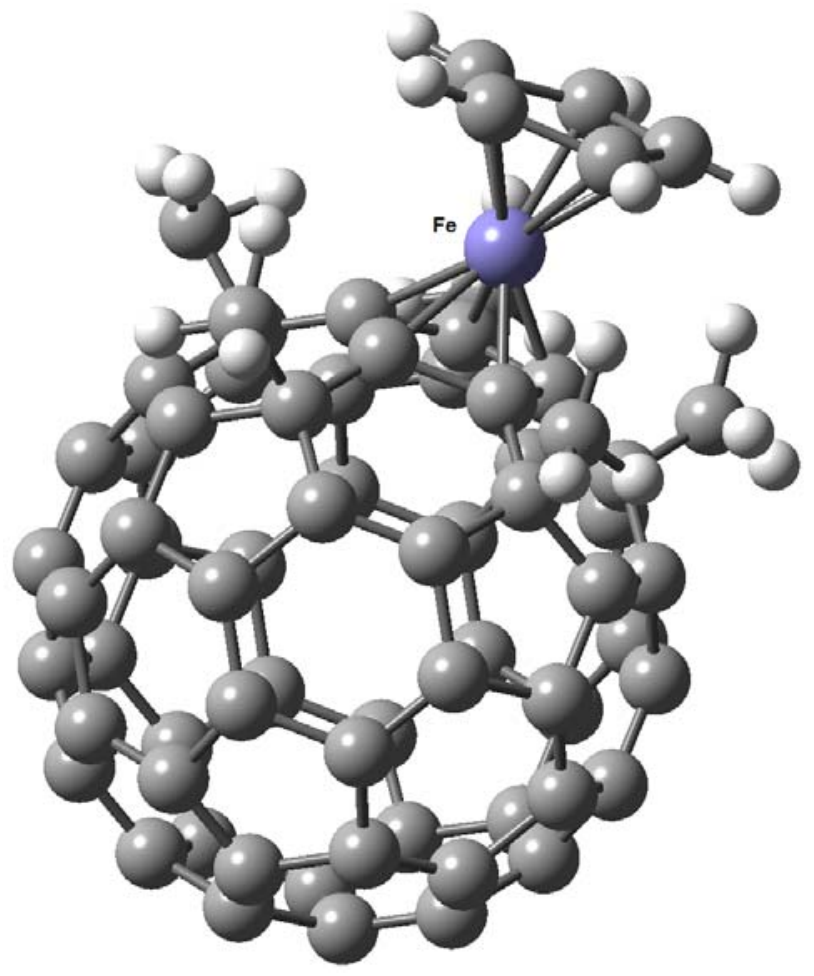

In another work, Nakamura [47] describes the existence of a ferrocene/ $\mathrm{C}_{70}$-fullerene hybrid; in this case only three peripheral organic groups are sufficient to form the complex (Figure 11). The structural features of the ferrocene moiety with $\mathrm{C}_{70}$ are similar to those with $\mathrm{C}_{60}$. With a small but significant difference between ferrocene $/ \mathrm{C}_{60}$-fullerene and ferrocene $/ \mathrm{C}_{70}$-fullereneis that the cyclopentadienide $\mathrm{C}-\mathrm{C}$ bond $\left(1.458 \AA\right.$ ) connected to a hexagon in the "belt region" of $\mathrm{C}_{70}$-fullerene core is slightly longer than the remaining four $\mathrm{C}-\mathrm{C}$ bonds in the pentagon, a known feature in the case of indenyl iron complexes. Bond alternation found in the six-member ring next to the cyclopentadienide moiety is another characteristic pertaining to indenyl complexes (see Figure 12). 
Figure 11. Molecular structure of ferrocene $/ \mathrm{C}_{70}$-fullerene hybrid, determined by $\mathrm{X}$-ray diffraction (Reproduced from [47] with permission).

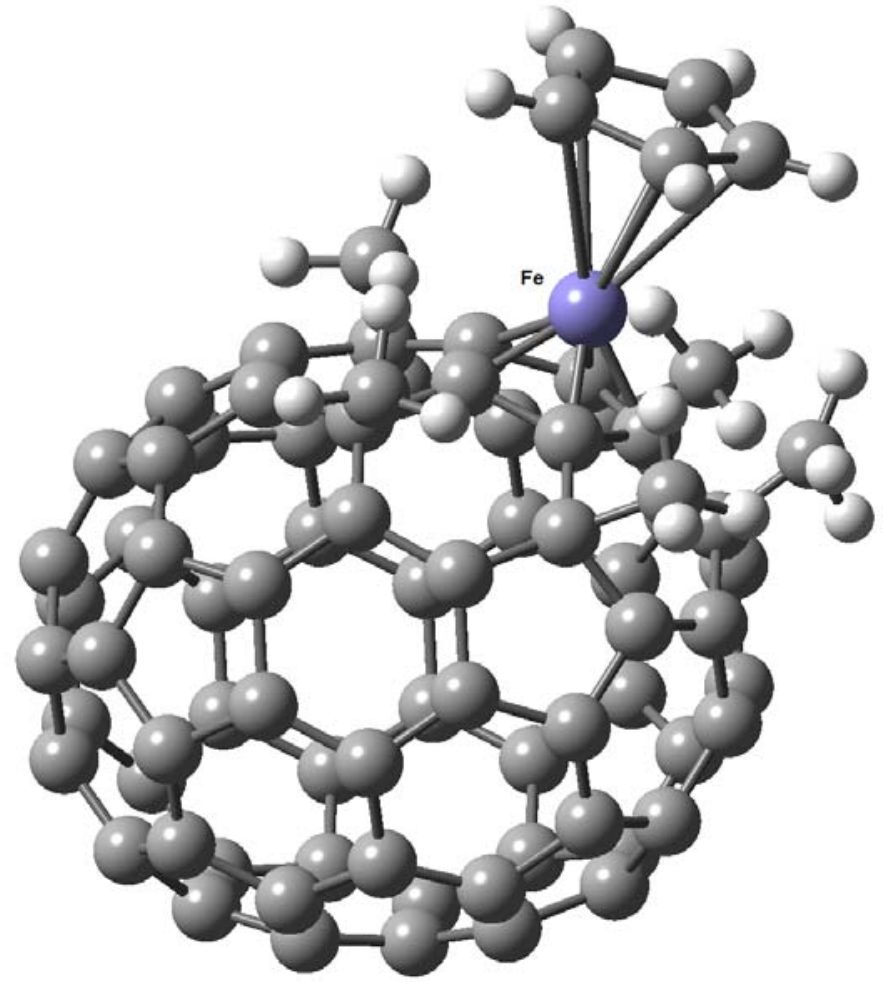

Figure 12. Indenyl iron(II) structure identified in ferrocene $/ \mathrm{C}_{70}$-fullerene hybrid (A) compared to that from $\mathrm{Fe}\left(\eta^{5} \text {-indenyl }\right)_{2}$ (B). Bond lengths are in angstroms deviation (Reproduced from [47] with permission).

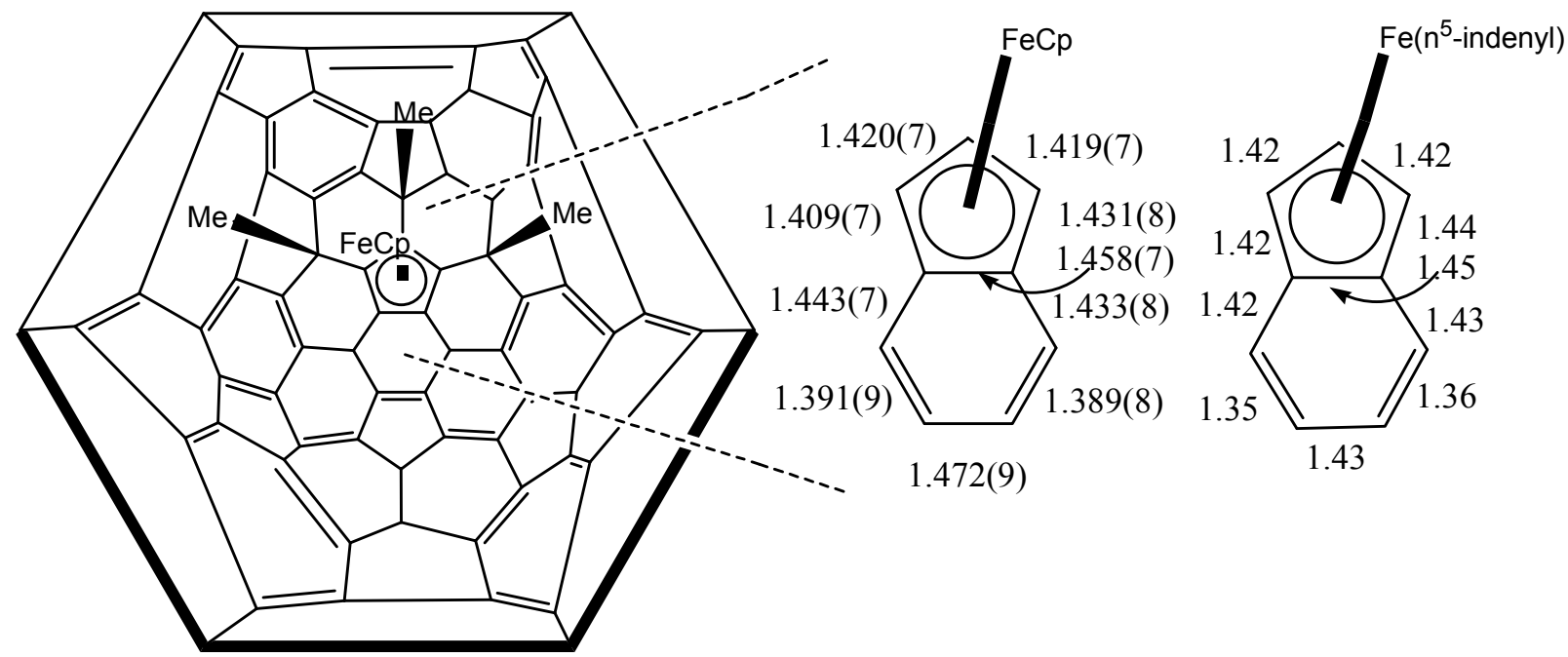

(A)

(B)

Further analysis of this hybrid system made clear the unusual stability of the penta-adduct in water, which serves as a precursor to the pentahaptofullerene metal complexes $M\left(\eta^{5}-C_{60} R_{5}\right)$. These compounds represent a rare example of hydrocarbon anions with well-defined water solubility [44]. Consequently, it is not only expected that diverse biological activities will be identified, but also that it will be feasible to create ordered aggregate structures that can be utilized in material science. 
Other successful examples of these systems include: (a) the synthesis of complex $\mathrm{Rh}\left(\eta^{5}-\mathrm{C}_{60} \mathrm{R}_{5}\right)(\mathrm{CO})_{2}$, [47], where the average value of $\mathrm{Rh}-\mathrm{C}(\mathrm{Cp}$ of fullerene) distances are shorter when $\mathrm{R}=\mathrm{Me}$, than when $\mathrm{R}=\mathrm{Ph}, 2.26 \AA$ and $2.29 \AA$, respectively; (b) the synthesis of rhenium-hydrofullerene complexes, $(\mathrm{CO})_{3}-\mathrm{Re}-\eta^{5}-\mathrm{C}_{60}(\mathrm{H})_{3}\left(\mathrm{PhCH}_{2}\right)_{2}(\mathrm{Ph})$ [48] and the modification of R-groups in $\mathrm{M}-\eta^{5}-\mathrm{C}_{60} \mathrm{R}_{5}$ $(\mathrm{M}=\mathrm{Re}, \mathrm{Fe})$ by different alkil groups in order to identify new applications in biology, chemistry and other material sciences [49]; (c). The complex with ruthenium(II) where starting from $\mathrm{Ru}\left(\eta^{5}-\mathrm{C}_{60} \mathrm{R}_{5}\right) \mathrm{Cl}(\mathrm{CO})_{2}$, the carbonyl ligands can be cleanly replaced in order to obtain the phosphine and isonitrile complexes, without causing cleavage of the fullerene-metal bond [50]. In this work the authors propose that synthesized Ru-complexes can be applied to catalytic reactions both under neutral and reductive conditions; (d). For complexes with $\operatorname{Ir}(\mathrm{I})$ [51], $\operatorname{Ir}\left(\eta^{5}-\mathrm{C}_{60} \mathrm{Me}_{5}\right)(\mathrm{CO})_{2}$ which was obtained as starter material stands out. According to electrochemical analysis, this complex is very robust even under harsh reduction. X-ray diffraction study has revealed that Ir-C distance is slightly longer than that of the $\mathrm{Cp}$ analogue $(2.30 \AA$ vs. $2.26 \AA)$. The $\operatorname{Ir}\left(\eta^{5}-\mathrm{C}_{60} \mathrm{Me}_{5}\right)(\mathrm{CO})_{2}$ complex, and unlike its analogue in $\eta^{2}$ is quite stable toward molecular oxygen, water and heat $\left(100{ }^{\circ} \mathrm{C}\right)$ both as a solution and also as a solid, therefore representing an improved system for future applications.

A relationship between $\eta^{5}$ and $\eta^{4}$ and $\eta^{3}$ has been suggested by Nakamura in some of the works cited here; indeed Chistyakov and his co-workers theoretically follow this possible transformation [52]. They have studied the molecular and electronic structures of the $(\mathrm{CpFe})-\mathrm{C}_{60} \mathrm{H}_{10}-(\mathrm{FeCp})$ complex of the $D_{5 d}$ symmetry, where $\mathrm{Cp}$ is the cyclopentadienyl radical, by applying the ab initio Hartree-FockRoothaan method in the 3-21G basis set. Each FeCp semi-sandwich moiety is linked to atoms of one five-member ring, arranged on the opposite faces of fullerene, by the $\eta^{5}-\pi$-type bond (Figure 13). It is apparent that the energy of the $\eta^{5}-\pi$-Fe- $\mathrm{C}_{60} \mathrm{H}_{10}$ bonds in the $(\mathrm{CpFe})_{2} \mathrm{C}_{60} \mathrm{H}_{10}$ complex is comparable to that of the $\eta^{5}-\pi$-Fe- $\mathrm{Cp}$ bond in the $\mathrm{FeCp}_{2}$ ferrocene molecule $(\sim 78 \mathrm{kcal} / \mathrm{mol})$. This system is of particular interest for the formation of quasi-linear polymers with conducting properties.

Figure 13. Complex $2 \eta^{5}-\pi-(\mathrm{CpFe})_{2}-\mathrm{C}_{60} \mathrm{H}_{10}[51]$.

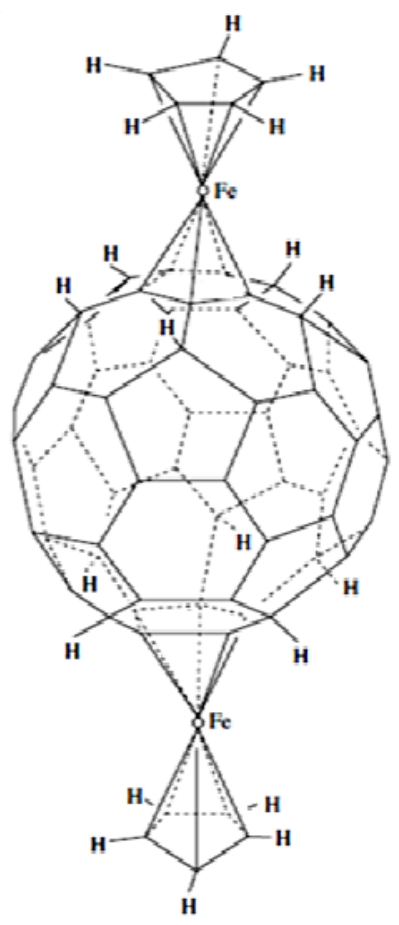


This same idea, i.e., that of double-decker ferrocene complexes was also studied by the Nakamura group [53,54]. They carried out works following both theoretical and experimental arguments and found that the addition of a second ferrocene fragment caused strong instability and may generate very short-lived radical-ion pairs.

This particular coordination mode has been particularly studied (along with $\eta^{2}$ ) because of the large number of compounds created by Nakamura. Importantly, although Nakamura and his colleagues [55] published some articles about his work, however it appears that certain areas have been left for other research groups to develop [56].

\section{7. $\eta^{6}$ Hapticity}

Several authors have mentioned the particular limitation of fullerenes, when attempting to form $\eta^{6}$ complexes. Lichtenberg and his co-workers [11,12] presented the results of quantum chemical calculations where they identify attractive interaction for metal atoms only in the cases of $\eta^{2}$ and $\eta^{5}$ coordination modes, with the former being predominant.

Chistyakov and his group [40] compared $\eta^{5}$ and $\eta^{6}$ cases again using theoretical methods and also concluded that $\eta^{6}$ is not a good example. However Stankevich and his group [43,57] indicate that a perturbation of the system, consistent with the addition of $\mathrm{R}$ groups to the surface of the $\mathrm{C}_{60}$ in six $\alpha$ positions with respect to a common six-member ring is able to stabilize the coordination of a metal atom in $\eta^{6}$ manner. A similar calculation was performed by Rogers and Marynick [41] considering an $\mathrm{C}_{60} \mathrm{Cr}(\mathrm{CO})_{3}$ complex, where they concluded that the binding energy is lower than in the case of an analogous compound containing only a benzene ring instead of the fullerene, but they concluded that the complex should be stable.

In the experimental context, two reports have cited possible $\eta^{6}$ complexes. Firstly, Peng and his group [34] prepared $\mathrm{C}_{60} \mathrm{RuCp}(\mathrm{Me})_{5}$ and by analyzing mass spectroscopy data they proposed that the coordination in this compound is $\eta^{6}$. Secondly Taylor and his co-workers [58] have prepared a molybdenum organometallic derivative of $\mathrm{C}_{60}$ with the polysubstitution of fluorine atoms and suggested that this coordination is also $\eta^{6}$, although the $\mathrm{C}_{60}$ sphere manifests a strong distortion.

Salcedo carried out simulations on two possible kinds of compounds (see Figure 14). In the first instance, he proposed the possibility of an analogy of dibenzen-chromium [59] but with $\mathrm{C}_{60}$ fullerenes present, instead of the normal benzene rings. His calculations indicate a very stable species. In the second instance, a mixed complex, where there is a $\mathrm{C}_{60}$ on one side and a benzene ring on the other is also analyzed. It is of note that both molecules demonstrate interesting electronic behavior and can be considered to represent semiconductor species.

A possible problem for the $\eta^{6}$ coordination would appear to be the curvature of the fullerenes $[13,60]$. One way to avoid this situation would be to prepare organometallic compounds of fullerenes larger than $\mathrm{C}_{60}$ and $\mathrm{C}_{70}$. This topic was discussed in the article by Molina, Pérez-Manríquez and Salcedo [61] where they carried out an interesting comparison of all possible isomeric complexes with the formula $\mathrm{C}_{80} \mathrm{CrC}_{6} \mathrm{H}_{6}$ (Figure 15). The results show that compounds derived from $\mathrm{C}_{2 \mathrm{v}}, \mathrm{D}_{2}, \mathrm{D}_{3}$ and $\mathrm{D}_{5 \mathrm{~d}}$ isomers of $\mathrm{C}_{80}$ will comprise $\eta^{6}$ stable species with interesting electronic characteristics. 
Figure 14. Hybrid compounds suggested by Salcedo [59].
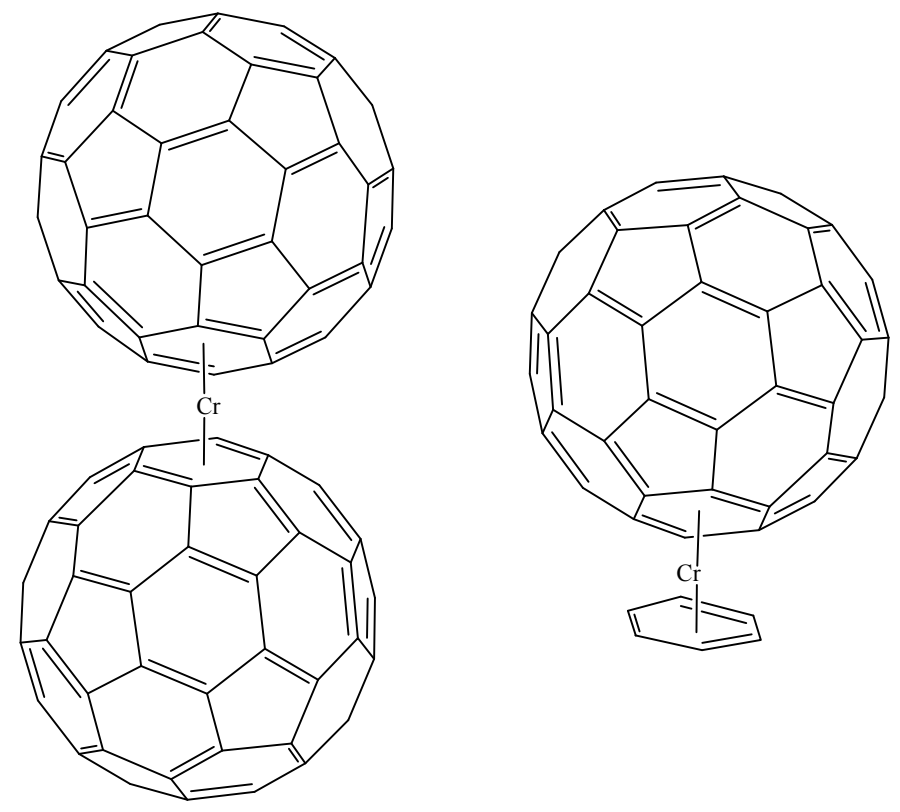

Figure 15. The six isomers of $\mathrm{C}_{80} \mathrm{CrC}_{6} \mathrm{H}_{6}$ [61].

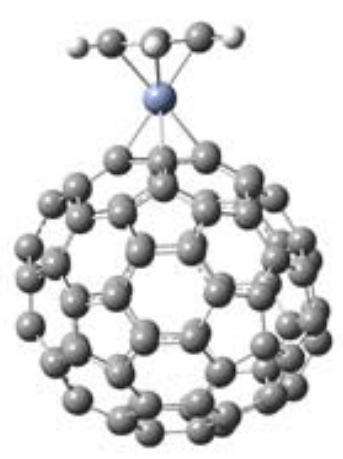

(a) $\mathrm{C}_{2 \mathrm{v}}$

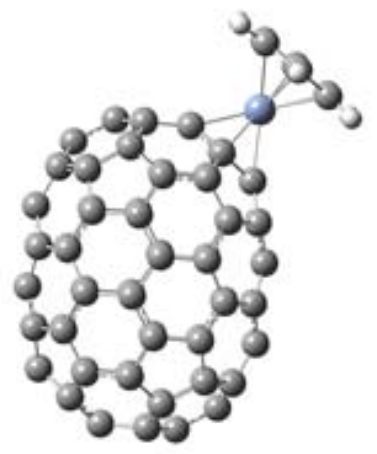

(d) $\mathrm{D}_{5 \mathrm{~d}}$

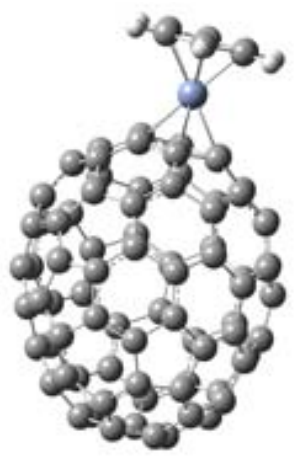

(b) $\mathrm{D}_{2}$

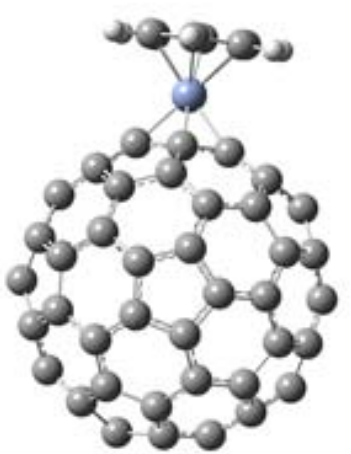

(e) $\mathrm{D}_{5 \mathrm{~h}}$

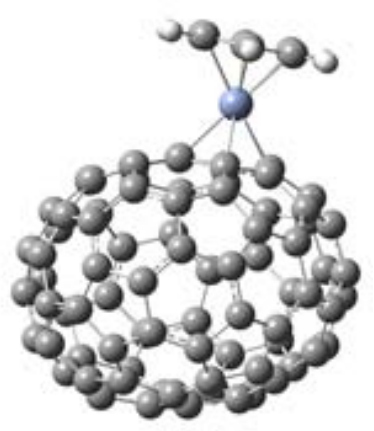

(c) $\mathrm{D}_{3 \mathrm{~d}}$

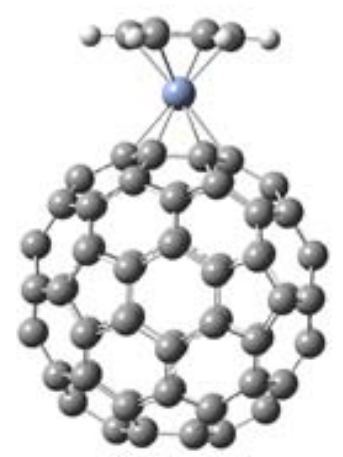

(f) $\mathrm{I}_{\mathrm{h}}$

\section{Conclusions}

The great majority of fullerene organometallic compounds belong to two groups; those with $\eta^{2}$ and those with $\eta^{5}$ hapticities, however some examples of this type of compound manifest the other four possible hapticities; thus the field is open and there are several opportunities for working on theoretical [62] 
as well as experimental [63] projects for the purpose of studying these structures, their applications and reaching an understanding of both bond and reactivity trends.

\section{Acknowledgement}

We want to acknowledge both Oralia L. Jiménez and María Teresa Vázquez for their technical support. We would also like to thank Caroline Karslake, M.A. (Social Anthropology, Cambridge University, England) for reviewing the grammar and style of the text in English.

\section{References and Notes}

1. Fagan, P.J.; Calabrese, J.C.; Malone, B. The chemical nature of buckminsterfullerene and the characterization of a platinum derivative. Science 1991, 252, 1160-1161.

2. Hawkins, J.M.; Meyer, A.; Lewis, T.A.; Loren, S.; Hollander, F.J. Crystal structure of osmilated $\mathrm{C}_{60}$. Confirmation of the soccer ball framework. Science 1991, 252, 312-313.

3. Krätschmer, W.; Lamb; L.D.; Fastiropoulus, K.; Huffman, D.R. Solid $\mathrm{C}_{60}$ a new form of carbon. Nature 1990, 347, 354-356.

4. Kroto, H.W.; Heath, J.R.; O’Brien, S.C.; Curl, R.F.; Smalley, R.E. C 60 -Buckminsterfullerene. Nature 1985, 318, 162-163.

5. Balch, A.L.; Olmstead, M.M. Reactions of Transition Metal Complexes with Fullerenes $\left(\mathrm{C}_{60}, \mathrm{C}_{70}\right.$, etc.) and Related Materials. Chem. Rev. 1998, 98, 2123-2165.

6. Shinohara, H. Endohedral metallofulerenes. Rep. Prog. Phys. 2000, 63, 843-892.

7. Rodríguez-Fortea, A.; Balch, A.L.; Poblet, J.M. Endohedral metallofullerenes: A unique host-guest association. Chem. Soc. Rev. 2011, 40, 3551-3563.

8. Osuna, S.; Swart, M.; Solà, M. The reactivity of endohedral fullerenes. What can be learnt from computational studies? Phys. Chem. Chem. Phys. 2011, 13, 3585-3603.

9. Yang, S.; Liu, F.; Chen, C.; Jiao, M.; Wei, T. Fullerenes encaging metal clustersClusterfullerenes. Chem. Commun. 2011, 47, 11822-11839.

10. Hirsch, A.; Lamparth, I.; Karfunkel, P.D.H.R. Fullerene Chemistry in three dimensions: Isolation of seven regioisomeric bisadducts and chiral trisadducts of $\mathrm{C}_{60}$ and di(ethoxicarbonyl)methylene, Angew. Chem. Int. Ed. Engl. 1994, 33, 437-438.

11. Lichtenberger, D.L.; Wright, L.L.; Gruhn, N.E.; Rempe, M.E. Electronic structure of exohedral interactions between $\mathrm{C}_{60}$ and transition metals, J. Organomet. Chem. 1994, 478, 213-221.

12. Lichtenberger, D.L.; Wright, L.L.; Gruhn, N.E.; Rempe, M.E. Electronic structure and bonding of $\mathrm{C}_{60}$ to metals. Synth. Metals 1993, 59, 353-367.

13. Sokolov, V.I. Fullerenes as a new type of ligands for transition metals. Russ. J. Coord. Chem. 2007, 33, 723-737.

14. Song, H.; Lee, K.; Park, J.T.; Chang, H.Y.; Choi, M.-G. Fluxional process and structural characterization of $\mu_{3}-\eta^{2} \eta^{2} \eta^{2}-\mathrm{C}_{60}$ triosmium cluster complexes, $\mathrm{Os}_{3}(\mathrm{CO})_{9-\mathrm{n}}\left(\mathrm{PMe}_{3}\right)_{n} \mu_{3}-\eta^{2} \eta^{2} \eta^{2}-\mathrm{C}_{60}$ $(\mathrm{n}=1,2,3)$. J. Organomet. Chem. 2000, 599, 49-56.

15. Usatov, A.V.; Martynova, E.V.; Dolgushin, F.M.; Peregudov, A.S.; Antipin, M.Y.; Novikov, Y.N. Selective insertion of dioxygen into an $\left(\eta^{2}-\mathrm{C}_{60}\right)$-Ir bond: Synthesis and Structure of the first metallacyclic complex with a $\sigma$-coordinated fullerene molecule. Eur. J. Inorg. Chem. 2003, 29-33. 
16. Zhang, S.; Brown, T.L.; Du, Y.; Shapley, J.R. Metalation of $\mathrm{C}_{60}$ with pentacarbonylrhenium radicals. Reversible formation of $\left\{\mathrm{C}_{60}-\mathrm{Re}\left(\mathrm{CO}_{5}\right)\right\}_{2}$. J. Am. Chem. Soc. 2003, 115, 6705-6709.

17. Arce, M.J.; Viado, A.L.; An, Y.-Z.; Khan, S.I.; Rubin, Y. Triple scission of a six membered ring on the surface of $\mathrm{C}_{60}$ via consecutive pericyclic reactions and oxidative cobalt insertion. J. Am. Chem. Soc. 1996, 118, 3775-3776.

18. Han, Y.-K.; Kim, K.H.; Kim, J.C.; Park, B.K.; Park, J.T. 60-Fullerene metal cluster complexes: Understanding $\eta^{1}$ and $\eta^{2[6,5]}$ bonding modes of metallofullerenes. Eur. J. Inorg. Chem. 2010, 1530-1535.

19. Olmstead, M.M.; Maitra, K.; Balch, A.L. Formation of a curved silver nitrate network that conforms to the shape of $\mathrm{C}_{60}$ and encapsulated the fullerene-Structural characterization of $\mathrm{C}_{60}\left\{\mathrm{Ag}\left(\mathrm{NO}_{3}\right)\right\}_{5}$. Angew. Chem. Int. Ed. Engl. 1999, 38, 231-233.

20. Song, H.; Lee, K.; Choi, M.-G.; Park, J.T. [60]Fullerene as a versatile four electron donor ligand. Organometallics 2002, 21, 1756-1758.

21. Konarev, D.V.; Khasanov, S.S.; Otsuka, A.; Lyubovskaya, R.N.; Yoshida, Y.; Otsuka, A. The interaction of $\mathrm{C}_{60}, \mathrm{C}_{70}$ and $\mathrm{C}_{60}(\mathrm{CN})_{2}$ radical anions with cobalt(II) tetraphenylporphyrin in solid multicomponent complexes. Chem. Eur. J. 2003, 9, 3837-3848.

22. Konarev, D.V.; Khasanov, S.S.; Otsuka, A.; Otsuka, A.; Lyubovskaya, R.N. Peculiarities of $\mathrm{C}_{60}{ }^{-}$ coordination cobalt(II) octaethylporphyrin in ionic multicomponent complexes: Observation of the reversible formation of $\mathrm{Co}-\mathrm{C}\left(\mathrm{C}_{60}{ }^{-}\right)$coordination bonds. Chem. Eur. J. 2006, 12, 5225-5230.

23. Howard, J.A.; Tomietto, M.; Wilkinson, D.A. Electron Paramagnetic Resonance study of the reaction of $\mathrm{Ag}$ atoms with $\mathrm{C}_{60}$ in cyclohexane on a rotating cryostat. J. Am. Chem. Soc. 1991, 113, 7870-7872.

24. Kim, H.H.; Jung, J.; Han, Y.-K. Geometric and electronic structures of $\mathrm{Os}_{3}(\mathrm{CO})_{9}\left(\mu^{3}-\eta^{2} \eta^{2} \eta^{2}-\mathrm{C}_{60}\right)$, $\mathrm{Os}_{3}(\mathrm{CO})_{8}\left(\mathrm{P}\left(\mathrm{CH}_{3}\right)_{3}\left(\mu^{3}-\eta^{2} \eta^{2} \eta^{2}-\mathrm{C}_{60}\right)\right.$ and their anions $(\mathrm{Q}=-1$ to -4$)$ : Reduction induced conversion of $\pi$ to $\sigma \mathrm{C}_{60}-$ Metal complexes. Organometallics 2004, 23, 3865-3869.

25. Bashilov, V.V.; Petrovski, P.V.; Sokolov, V.I. Synthesis of the first optically active organometallic fullerene derivative by $\eta^{2}$ functionalization of buckminsterfullerene by $\operatorname{Pd}(0)$ complexes. Russ. Chem. Bull. 1993, 42, 392-393.

26. Hawkins, J.M.; Meyer, A.; Lewis, T.A. Crystal structure of osmilated $\mathrm{C}_{60}$. Confirmation of the soccer ball framework. Science 1991, 252, 312-313.

27. Wu, Y.-Y.; Yeh, W.-Y. Synthesis of diphosphino-fullerene 1,2,4,15-( $\left(\mathrm{PPh}_{2}\right)_{2}(\mathrm{H})_{2} \mathrm{C}_{60}$ and its complexation with triosmium carbonyl complexes. Organometallics 2011, 30, 4792-4795.

28. Chen, C.-S.; Lin, C.-S.; Yeh, W.-Y. Synthesis of $\mathrm{Mo}(\mathrm{CO})_{2}\left(\eta^{3}-\mathrm{PPh}_{2}\left(o-\mathrm{C}_{6} \mathrm{H}_{4}\right) \mathrm{C}(=\mathrm{O}) \mathrm{H}\right)_{2}$ and its reaction with $\mathrm{C}_{60}$. J. Organomet. Chem. 2011, 696, 1474-1478.

29. Ivanova, V.N. Fullerene compounds with transition metals $\mathrm{M}_{\mathrm{n}} \mathrm{C}_{60}$ : Preparation, structure and properties. J. Struct. Chem. 2000, 41, 135-148.

30. Nunzi, F.; Sgamellotti, A.; Re, N.; Floriani, C. A density functional study of $\mathrm{C}_{60}$ transition metal complexes. Organometallics 2000, 19, 1628-1634.

31. Chatt, J.; Duncanson, L.A. Olefin co-ordination compounds. Part III. Infra-red spectra and structure: attempted preparation of acetylene complexes. J. Chem. Soc. 1953, 2939-2947.

32. Dewar, M.J.S.; Ford, G.P. Relationship between olefinic .pi. complexes and three membered rings. J. Am. Chem. Soc. 1979, 101, 783-791. 
33. Loboda, O. A DFT study on exohedral metallofullerenes: Structural and electronic properties. Fuller. Nanotub. Carbon Nanostruct. 2009, 17, 457-475.

34. Mavunkal. I.J.; Chi, Y.; Peng, S.M.; Lee, G.-H. Preparation and Structure of $\mathrm{Cp}_{2}{ }_{2} \mathrm{Ru}_{2}(\mu-\mathrm{Cl})(\mu-\mathrm{X}) \mathrm{C}_{60}, \mathrm{X}=\mathrm{H}, \mathrm{Cl}$. Novel Dinuclear Fullerene Complexes with and without Direct Ruthenium-Ruthenium Bonding. Organometallics 1995, 14, 4454-4456.

35. Hsu, H.-F.; Wilson, S.R.; Shapley, J.R. Triruthenium cluster complexes of $\mathrm{C}_{70}$. Synthesis and structural characterization of $\left.\left\{\mathrm{Ru}_{3}(\mathrm{CO})_{9}\right\}_{x}\left(\mu_{3}-\eta^{2}, \eta^{2}, \eta^{2}-\mathrm{C}_{70}\right)\right](\mathrm{x}=1,2)$. Chem. Commun. 1997, 12, $1125-1126$.

36. Chen, Z.; King, R.B. Spherical aromaticity: Recent works in fullerenes, polyhedral boranes and related structures. Chem. Rev. 2005, 105, 3613-3642.

37. Stankevich, I.V.; Sokolov, V.I. Advances in fullerene chemistry. Russ. Chem. Bull. Int. Ed. 2004, $53,1824-1845$.

38. Stankevich, I.V.; Chistyakov, A.L. Metal complexes of allyl derivatives of $\mathrm{C}_{60}$ fullerene: Molecular and electronic prediction from density functional calculations. Russ. Chem. Bull. 2003, $52,1272-1279$.

39. Halim, M.; Kennedy, R.D.; Suzuki, M.; Khan, S.I.; Diaconescu, P.L.; Rubin, Y. Complexes of gold(I), silver and cooper with pentaaryl [60] fulleride. J. Am. Chem. Soc. 2011, 133, 6841-6851.

40. Chistyakov, A.L.; Stankevich, I.V. On the possibility of existence of $\eta^{4}-\pi$ complexes of corannulene $\left(\mathrm{C}_{20} \mathrm{H}_{10}\right)$ and $\mathrm{C}_{60}$ fullerene derivatives. Russ. Chem. Bull. 2002, 51, 230-239.

41. Rogers, J.R.; Marynick, D.S. Theoretical estimates of the $\eta^{6}$ bonding capability of buckminsterfullerene in transition metal complex. Chem. Phys. Lett. 1993, 205, 197-199.

42. Kang, H.S. A theoretical study of fullerene-ferrocene hybrids. J. Comp. Chem. 2006, 28, 594-600.

43. Chistyakov, A.L.; Stankevich, I.V. Cyclopentadienyl type $\eta^{5}-\pi$-complexes of $\mathrm{C}_{60}$ fullerene derivatives with indium and thalium: Simulation of molecular and electronic structure by the MNDO/PM3 method. Russ. Chem. Bull. 1997, 46, 1832-1837.

44. Nakamura, E. Bucky ferrocene: Hybrid of ferrocene and fullerene. Pure Appl. Chem. 2003, 75, 427-434.

45. Sawamura, M.; Kuninobu, Y.; Toganoh, M.; Matsuo, Y.; Yamanaka, M.; Nakamura, E. Hybrid of ferrocene and fullerene. J. Am. Chem. Soc. 2002, 124, 9354-9355.

46. Nakamura, E.; Sawamura, M. Chemistry of $\eta^{5}$-fullerene metal complexes. Pure Appl. Chem. 2001, 73, 355-359.

47. Kaji, T.; Shimada, T.; Inoue, H.; Kuninobu, Y.; Matsuo, Y.; Nakamura, E.; Saiki, K. Molecular orientation and electronic structure of epitaxial bucky ferrocene $\left(\mathrm{Fe}\left(\mathrm{C}_{60}\left(\mathrm{Ch}_{3}\right)_{5}\right) \mathrm{C}_{5} \mathrm{H}_{5}\right)$ thin films. J. Phys. Chem. B 2004, 108, 9914-9918.

48. Toganoh, M.; Matsuo, Y.; Nakamura, E. Rhenium templated regioselective polyhydrogenation reaction of [60] Fullerene. Angew. Chem. 2003, 115, 3654-3656.

49. Toganoh, M.; Matsuo, Y.; Nakamura, E. Synthesis of ferrocene/hydrofullerene hybrid and functionalized bucky ferrocenes. J. Am. Chem. Soc. 2003, 125, 13974-13975.

50. Matsuo, Y.; Nakamura, E. Ruthenium (II) complexes of pentamethylated [60] fullerene. Alkyl, alkynyl, chloro, isocyanide and phosphine complexes. Organometallics 2003, 22, 2554-2563.

51. Matsuo, Y.; Iwashita, A.; Nakamura, E. Synthesis and derivatization of iridium (I) and Iridium (III) pentamethyl [60] fullerene complexes. Organometallics 2005, 24, 89-95. 
52. Gal'pern, E.G.; Stankevich, I.V.; Chistyakov, A.L. Modeling of the molecular and electronic structures of multiple decker sandwich macromolecules with $\eta^{5}-\pi$ bonds on the basis of biscyclopentadienyl derivatives $\mathrm{C}_{60} \mathrm{H}_{10}$ of a $\mathrm{C}_{60}$ fullerene. Phys. Sol. State 2001, 43, 989-992.

53. Matsuo, Y.; Tahara, K.; Nakamura, E. Synthesis and electrochemistry of double-decker buckyferrocenes. J. Am. Chem. Soc. 2006, 128, 7154-7155.

54. Marczak, R.; Wielopolski, M.; Gayathri, S.S.; Guldi, D.M.; Matsuo, Y.; Matsuo, K.; Tahara, K.; Nakamura, E. Uniquely shaped double decker buckyferrocenes-distinct donor-acceptor interactions. J. Am. Chem. Soc. 2008, 130, 16207-16215.

55. Nakamura, E.; Isobe, H. Functionalized fullerenes in water. The first 10 years of their chemistry, biology and nanoscience. Acc. Chem. Res. 2003, 36, 807-815.

56. Stewart, M.P.; Butterick, R., III.; Sneddon, R.G.; Matsuo, Y.; Geiger, W.E. Voltammetry of half sandwich manganese group complexes of $\eta 6-\mathrm{PhC} 3 \mathrm{~B} 7 \mathrm{H} 9$ and $\eta 5 \mathrm{C} 60 \mathrm{Bn} 2 \mathrm{PhH} 2$, two ligands that are cyclopentadienyl mimics. Inorg. Chim. Acta 2010, 364, 251-254.

57. Gal'pern, E.G.; Gambaryan, N.P.; Stankevich, I.V.; Chistyakov, A.L. Fullerene $C_{60}$ as a $\eta^{5}$ and $\eta^{6}$ ligand in sandwich type $\pi$-complexes with transition metals. Russ. Chem. Bull. 1994, 43, 547-550.

58. Francis, M.D.; Boltalina, O.V.; Nixon, J.F.; Taylor, R. Evidence for $\eta^{6}$ coordination to a fullerene. Fuller. Nanotub. Carbon Nanostruct. 2004, 11, 115-121.

59. Salcedo, R. Fullerenocene. Polyhedron 2009, 28, 431-436.

60. Sokolov, V.I.; Gasanov, R.G.; Goh, L.Y.; Weng, Z.; Chistyakov, A.L.; Stankevich, I.V. (Cyclopentadienyl) Chromiumtricarbonyl dimers as a source of metal-centered free radicals to form stable- $\eta^{5}$ bonded spin-adducts with fullerene. J. Organomet. Chem. 2005, 690, 2370-2375.

61. Molina, B.; Pérez-Manríquez, L.; Salcedo, R. On the $\pi$ coordination of organometallic fullerene complexes. Molecules 2011, 16, 4652-4659.

62. Poater, J.; Fradera, X.; Durán, M.; Solà, M. An insight into the local aromaticities of polycyclic aromatic hydrocarbons and fullerenes. Chem. Eur. J. 2003, 9, 1113-1122.

63. Chen, S.-C.; Lin, C.-S.; Yeh, W.-Y. Synthesis of $\mathrm{Mo}(\mathrm{CO})_{2}\left(\eta^{3}-\mathrm{PPh}_{2}\left(\mathrm{o}-\mathrm{C}_{6} \mathrm{H}_{4}\right) \mathrm{C}(=\mathrm{O}) \mathrm{H}\right)_{2}$ and its reaction with $\mathrm{C}_{60}$. J. Organomet. Chem. 2011, 696, 1474-1478.

(C) 2012 by the authors; licensee MDPI, Basel, Switzerland. This article is an open access article distributed under the terms and conditions of the Creative Commons Attribution license (http://creativecommons.org/licenses/by/3.0/). 